\title{
Systematic Review \\ Effect of Adjuvant and Palliative Chemotherapy in Large Cell Neuroendocrine Carcinoma of the Lung: A Systematic Review and Meta-Analysis
}

\author{
Hao Chen ${ }^{1, *,+}+{ }^{\circ}$, Masashi Ishihara ${ }^{1,+}{ }^{+}$, Nobuyuki Horita ${ }^{2}$, Hiroki Kazahari ${ }^{1}$, Ryusuke Ochiai ${ }^{1}$, Shigeru Tanzawa ${ }^{1}$, \\ Takeshi Honda ${ }^{1}$, Yasuko Ichikawa ${ }^{1}$, Kiyotaka Watanabe ${ }^{1}$ (I) and Nobuhiko Seki ${ }^{1, *}$ \\ 1 Division of Oncology, Department of Internal Medicine, Teikyo University School of Medicine, \\ Tokyo 173-8606, Japan; m.ishihara@med.teikyo-u.ac.jp (M.I.); kazahari0309@med.teikyo-u.ac.jp (H.K.); \\ ryo7132003@med.teikyo-u.ac.jp (R.O.); s.tanzawa@med.teikyo-u.ac.jp (S.T.); \\ thonda@med.teikyo-u.ac.jp (T.H.); icchi@med.teikyo-u.ac.jp (Y.I.); kiyowata@med.teikyo-u.ac.jp (K.W.) \\ 2 Department of Pulmonology, Yokohama City University Graduate School of Medicine, \\ Yokohama 236-0027, Japan; horitano@yokohama-cu.ac.jp \\ * Correspondence: chinsmd@gmail.com (H.C.); nseki@med.teikyo-u.ac.jp (N.S.) \\ + Hao Chen and Masashi Ishihara contributed equally to the work.
}

check for updates

Citation: Chen, H.; Ishihara, M.; Horita, N.; Kazahari, H.; Ochiai, R.; Tanzawa, S.; Honda, T.; Ichikawa, Y.; Watanabe, K.; Seki, N. Effect of Adjuvant and Palliative Chemotherapy in Large Cell Neuroendocrine Carcinoma of the Lung: A Systematic Review and Meta-Analysis. Cancers 2021, 13, 5948. https://doi.org/10.3390/cancers 13235948

Academic Editor: Sebastiano Mercadante

Received: 25 October 2021 Accepted: 24 November 2021 Published: 26 November 2021

Publisher's Note: MDPI stays neutral with regard to jurisdictional claims in published maps and institutional affiliations.

Copyright: (c) 2021 by the authors. Licensee MDPI, Basel, Switzerland. This article is an open access article distributed under the terms and conditions of the Creative Commons Attribution (CC BY) license (https:/ / creativecommons.org/licenses/by/ $4.0 /)$.
Simple Summary: Adjuvant chemotherapy revealed a better outcome than surgery only, but there was no statistical difference in patients with stage IA. The small cell lung cancer regimen (SCLC) was frequently selected in adjuvant chemotherapy. The SCLC regimen showed better survival than the non-SCLC regimen as palliative chemotherapy at the endpoint of the odds ratio of mortality after two years.

Abstract: Background: Pulmonary large cell neuroendocrine carcinoma (LCNEC) is a rare subset of lung carcinoma with poor overall survival. Methods: A systematic review following a meta-analysis of studies was performed to identify the effect of different selections of chemotherapy in LCNEC. Articles providing overall survival data for adjuvant chemotherapy or palliative chemotherapy for LCNEC were eligible. The odds ratio (OR) of mortality at one or two years after chemotherapy was evaluated. Results: A total of 16 reports were finally included in the quantitative synthesis, involving a total of 5916 LCNEC patients. Adjuvant chemotherapy was administered to 1303 patients, and palliative chemotherapy was administered to 313 patients using either a small cell lung cancer (SCLC) or a non-small cell lung cancer (NSCLC) regimen. The OR for adjuvant chemotherapy was 0.73 (95\% confidence interval (CI): 0.59 to $0.89, p=0.002$ ). The SCLC regimen showed an OR of 0.52 (95\% CI: 0.11 to $2.38, p=0.40$ ) after one year, and 0.32 (95\% CI: 0.11 to $0.89, p=0.03$ ) after two years, compared with the NSCLC regimen. Conclusions: Adjuvant chemotherapy for pulmonary large cell neuroendocrine carcinoma improved the outcome after surgery. The SCLC regimen showed better survival than the NSCLC regimen as palliative chemotherapy.

Keywords: large cell neuroendocrine carcinoma of the lung; chemotherapy; regimen; small cell lung cancer; non-small cell lung cancer

\section{Introduction}

Pulmonary large cell neuroendocrine carcinoma (LCNEC) is a rare subset of lung carcinoma with poor overall survival; it accounts for less than $3 \%$ of all lung malignancies. According to the 2015 World Health Organization criteria, high-grade neuroendocrine carcinomas of the lung are classified into two categories: LCNEC and small cell lung carcinoma (SCLC) [1]. Whereas typical cases of LCNEC are morphologically distinct from SCLC, the differentiation between LCNEC and SCLC can be challenging in some cases [2]. Because of the difficulties in diagnosing LCNEC, and its rarity, the optimal systemic treatment has not been established [3]. In the American Society of Clinical Oncology 
(ASCO) guidelines, either platinum plus etoposide or the same regimen as other patients with non-squamous carcinoma is advised for LCNEC [4].

There are limited data on the usage and selection of chemotherapy in early-stage and advanced-stage LCNEC. In early-stage LCNEC, the mainstay of treatment for the node-negative disease is surgical resection, and optimal adjuvant treatment strategies are not well defined. Adjuvant chemotherapy regimens are associated with varying efficacy in preventing tumor recurrence [5]. In advanced-stage LCNEC, SCLC regimens are more commonly used based on limited retrospective analyses, [6] and several studies showed that the genomic profile of LCNEC corresponds closely with that of SCLC $[7,8]$. Recently, it was suggested that there is an increase in overall survival (OS) in LCNEC patients when NSCLC regimens are adopted, especially gemcitabine-platinum rather than pemetrexedplatinum and etoposide-platinum (SCLC regimens) [9].

The standard chemotherapy for LCNEC is unclear. This study was designed to examine the effect of adjuvant and palliative chemotherapy for LCNEC. The effect of adjuvant chemotherapy was checked by comparing patients who underwent surgery plus adjuvant chemotherapy and surgery-alone patients. The effect of palliative chemotherapy was checked by comparing the effects of the SCLC and NSCLC regimens.

\section{Materials and Methods}

\subsection{Study Overview}

The protocol of this systematic review and meta-analysis followed the Preferred Reporting Items for Systematic Reviews and Meta-Analyses (PRISMA) statement and was registered on the website of the University Hospital Medical Information Network Clinical Trials Registration (UMIN000044028) [10,11]. Institutional review board approval was not required because of the nature of this study. The PRISMA checklist is shown in Table S1.

\subsection{Study Search}

Four major online databases, namely, PubMed, Web of Science, Cochrane, and Embase, were searched. The following formula was applied for PubMed: (large cell neuroendocrine carcinoma) OR (LCNEC) OR (high-grade neuroendocrine carcinomas) AND (chemotherapy). Two review authors (MI and HC) independently screened the titles and abstracts and carefully evaluated the full text to select eligible articles. In cases of discrepancy, they reached a consensus through discussion. Review articles, as well as original articles, were hand searched (MI and $\mathrm{HC}$ ) for additional research papers that met the inclusion criteria.

\subsection{Inclusion and Exclusion Criteria}

Full articles, brief reports, and conference abstracts published in any language that provided data for OS after chemotherapy for LCNEC were included. To be included, a study had to include: (1) patients with pulmonary LCNEC, (2) data outlining mortality two years after chemotherapy, and (3) numbers of patients in each group.

Exclusion criteria were as follows: (1) single-arm study, (2) SCLC was included and data for LCNEC could not be separated, and (3) staging information was not available.

\subsection{Quality Assessment}

The target population was patients with LCNEC. Commonly used pathological criteria were accepted, along with WHO 2015 criteria [12,13]. The SCLC regimen was platinum and etoposide or irinotecan; the NSCLC regimen was different combinations of platinum with gemcitabine, pemetrexed, docetaxel, paclitaxel, or vinorelbine.

\subsection{Risk of Bias}

Two reviewers independently assessed the methodological quality of selected studies using the Newcastle-Ottawa quality assessment, evaluating the quality of observational studies [14]. Disagreement between reviewers was discussed, and agreement was reached by consensus. 


\subsection{Outcomes}

Typically, five-year OS is the gold standard in adjuvant chemotherapy; the effect of adjuvant chemotherapy was checked by comparing the ORs of mortality in patients who underwent adjuvant chemotherapy or surgery alone at five years. In palliative chemotherapy, most of the studies reported OS after two years. The different effects of the SCLC and NSCLC regimens were checked by ORs of mortality one and two years after the different regimens.

\subsection{Data Extraction}

Two review authors, MI and HC, independently extracted data, including the name of the first author, publication year, publication country, staging, and regimen used in the treatment.

\subsection{Statistics}

All analyses were performed in Review Manager ver. 5.3 (Cochrane Collaboration, Oxford, UK). Figures illustrated using Review Manager were adjusted as necessary. Odds ratios were determined by calculating the numbers of surviving patients one or two years after chemotherapy. Heterogeneity evaluated with the $\mathrm{I}^{2}$ statistic was interpreted as follows: $\mathrm{I}^{2}=0 \%$ indicates no heterogeneity, $0 \%<\mathrm{I}^{2}<25 \%$ indicates the least heterogeneity, $25 \% \leq \mathrm{I}^{2}<50 \%$ indicates mild heterogeneity, $50 \% \leq \mathrm{I}^{2}<75 \%$ indicates moderate heterogeneity, and $75 \% \leq \mathrm{I}^{2}$ indicates strong heterogeneity [15]. A $p$-value of $<0.05$ was considered significant.

\section{Results}

\subsection{Study Search and Study Characteristics}

We identified 2872 articles, including 2870 articles through database search and 2 articles by hand search. There were 1056, 1658, and 100 articles left after removing duplication, screening, and full-article reading, respectively (Figure S1). We finally included 15 reports in quantitative synthesis, including a total of 6457 LCNEC patients. All of them were retrospective studies, and one study checked the effect of adjuvant chemotherapy by using propensity scores in matched pairs. The Newcastle-Ottawa Scale ranged from five to seven stars.

All of them were written in English. There were eight studies that compared the effect of adjuvant chemotherapy (Table 1) [16-23]. Among the nine reports, two were from Germany and USA, and there was one each from China, Canada, Japan, and Korea. Adjuvant chemotherapy was conducted in 1303 of 5603 LCNEC patients who underwent an operation. Detailed information on adjuvant chemotherapy was described in five studies. The SCLC regimen was more frequently selected than NSCLC in adjuvant chemotherapy, and one study used the SCLC regimen of adjuvant chemotherapy for all patients.

Table 1. Background and characteristics of studies of adjuvant chemotherapy.

\begin{tabular}{|c|c|c|c|c|c|c|c|c|}
\hline Author & Country & $\begin{array}{l}\text { No. of } \\
\text { Cases }\end{array}$ & $\begin{array}{l}\text { No. } \\
\text { Chemo }\end{array}$ & Nature & Age (y) & Stage & Regimen & NOS \\
\hline Han 2017 & China & 90 & 64 & Retro & 62 & I-III & 35 SCLC regimen; 29 NSCLC regimen & 6 \\
\hline Kim 2017 & Korea & 139 & 50 & Retro & 65 & I-IV & Paclitaxel or docetaxel plus platinum & 6 \\
\hline Kujtan 2018 & USA & 1232 & 275 & Retro & 66 & $\mathrm{I}$ & The regimen was not described & 5 \\
\hline Ogawa 2019 & Japan & 92 & 31 & Retro & 68 & I-III & $\begin{array}{l}20 \text { SCLC regimen; } 11 \text { NSCLC regimen } \\
\text { The regimen was not described; }\end{array}$ & 6 \\
\hline Raman 2019 & USA & 1755 & 300 & Retro & 66 & I & $\begin{array}{l}54 \text { cases of chemoradiation, } 46 \text { cases } \\
\text { of radiation }\end{array}$ & 5 \\
\hline Rieber 2015 & Germany & 66 & 32 & Retro & 63 & I-IV & 16 SCLC regimen; 16 NSCLC regimen & 6 \\
\hline Rossel 2016 & Germany & 118 & 62 & Retro & 64 & I-II & The regimen was not described & 5 \\
\hline Wakeam 2020 & Canada & 1017 & 463 & Retro & 67 & I-II & $\begin{array}{l}\text { The regimen was not described; } \\
33 \text { cases of radiation enrolled }\end{array}$ & 5 \\
\hline
\end{tabular}


Six studies compared the effect of chemotherapy in different regimens. A total of 131 cases of SCLC regimens and 182 cases of NSCLC regimens were conducted in the treatment of LCNEC (Table 2) $[6,9,16,24-26]$. Platinum plus etoposide or irinotecan was used in the SCLC regimen; different combinations of platinum were used in the NSCLC regimen. There were four studies that revealed detailed combinations of chemotherapy in the NSCLC regimen, and gemcitabine was the most frequently used. Only one study focused on the effect of different regimens in the treatment of stage IV LCNEC.

Table 2. Background and characteristics of studies of chemotherapy with a different regimen.

\begin{tabular}{|c|c|c|c|c|c|c|c|}
\hline Author & Country & $\begin{array}{l}\text { Total } \\
\text { Cases }\end{array}$ & $\begin{array}{l}\text { SCLC } \\
\text { Regimen }\end{array}$ & Stage & Age (y) & Details of the NSCLC Regimen & NOS \\
\hline Derks 2017 & Netherlands & 128 & 48 & IV & 65 & GEM 46; PEM 20; PTX 7; DOC 6; VNR 1 & 6 \\
\hline Eldessouki 2018 & USA & 15 & 9 & III-IV & 55 & Detailed information not available & 5 \\
\hline Han 2017 & China & 64 & 35 & I-III & 62 & $\begin{array}{l}\text { Platinum with GEM 9; VNR 8; PEM 7; } \\
\text { DOC } 5\end{array}$ & 6 \\
\hline Kozuki 2005 & Japan & 7 & 3 & III-IV & 64 & Platinum with DOC 2; GEM 2; VNR 1 & 6 \\
\hline Rossi 2005 & France & 55 & 25 & I-III & 65 & Detailed information not available & 5 \\
\hline Sun 2012 & Korea & 45 & 11 & I-IV & 64 & $\begin{array}{l}\text { Platinum with GEM 9; PTX 4; PEM 2; } \\
\text { DOC 2; VNR } 2\end{array}$ & 6 \\
\hline
\end{tabular}

SCLC: small cell lung cancer; NSCLC: non-small cell lung cancer; NOS: Newcastle-Ottawa Scale; GEM: gemcitabine; PEM: pemetrexed, PTX: paclitaxel, DOC: docetaxel; VNR: vinorelbine.

\subsection{Effect of Adjuvant Chemotherapy}

In 1458 cases of adjuvant chemotherapy of LCNEC, the mortality of patients was evaluated after adjuvant chemotherapy or surgery only, after five years. The OR of adjuvant chemotherapy was 0.65 (95\% confidence interval (CI): 0.53 to $0.80, p<0.01 ; \mathrm{I}^{2}=40 \%, p$ for heterogeneity $=0.11$ ) (Figure 1). Subgroup analysis of adjuvant chemotherapy in patients with stages I, IA, and IB was conducted separately. The OR in patients with stage I was 0.68 (95\% CI: 0.48-0.95, $p=0.02 ; \mathrm{I}^{2}=59 \%, p$ for heterogeneity $=0.06$ ) (Figure 2a), whereas ORs were 0.88 (95\% CI: $0.71-1.08, p=0.22 ; \mathrm{I}^{2}=0 \%, p$ for heterogeneity $\left.=0.75\right)$ (Figure $2 \mathrm{~b}$ ) and 0.49 (95\% CI: $0.32-0.73, p<0.01 ; \mathrm{I}^{2}=44 \%, p$ for heterogeneity $=0.17$ ) (Figure $2 \mathrm{c}$ ) in patients with stages IA and IB.

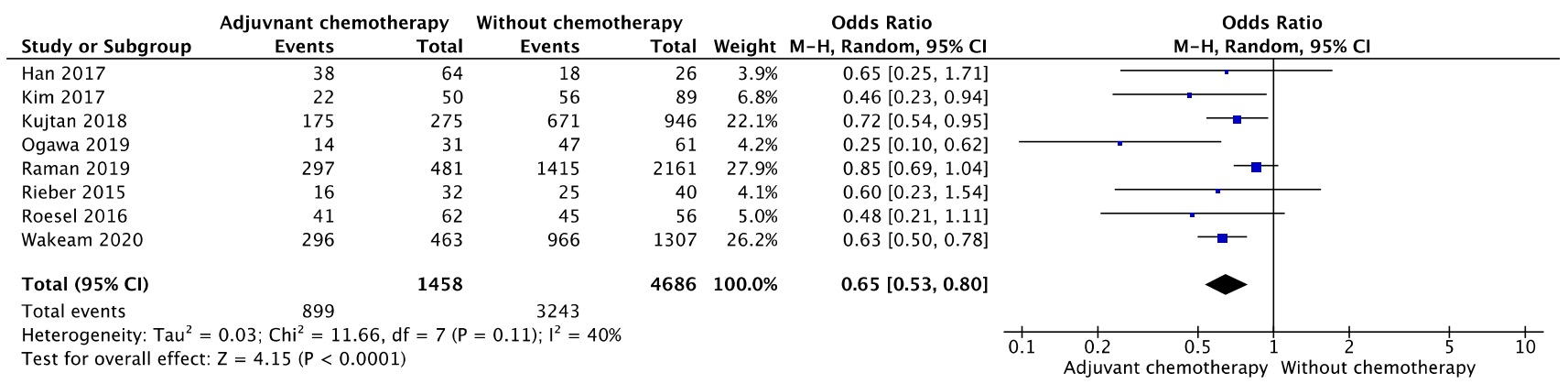

Figure 1. Effect of adjuvant chemotherapy after five years in patients of all stages.

\subsection{Effect of Different Regimens in Chemotherapy}

The OR of mortality was counted at one and two years after chemotherapy by the SCLC or NSCLC regimen separately. At the endpoint of one year after chemotherapy, there was no difference in the OR of SCLC and NSCLC regimens. The OR was 0.52 (95\% CI: 0.11 to $2.38, p=0.40 ; \mathrm{I}^{2}=71 \%, p$ for heterogeneity $=0.004$ ) (Figure 3a). However, the SCLC regimen showed a better effect than NSCLC two years after chemotherapy. The OR of the SCLC regimen was 0.32 (95\% CI: 0.11 to $0.89, p=0.03 ; \mathrm{I}^{2}=46 \%, p$ for heterogeneity $=0.10$ ) (Figure 3b). 
(a)

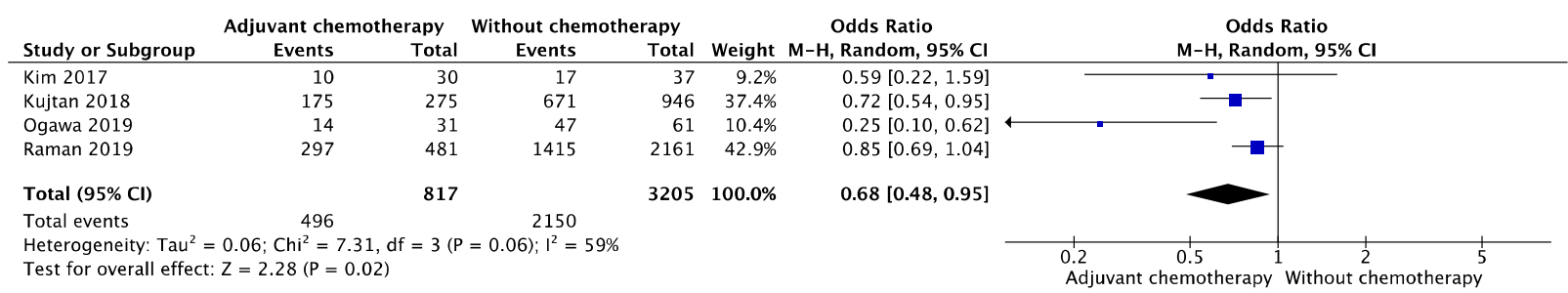

(b)

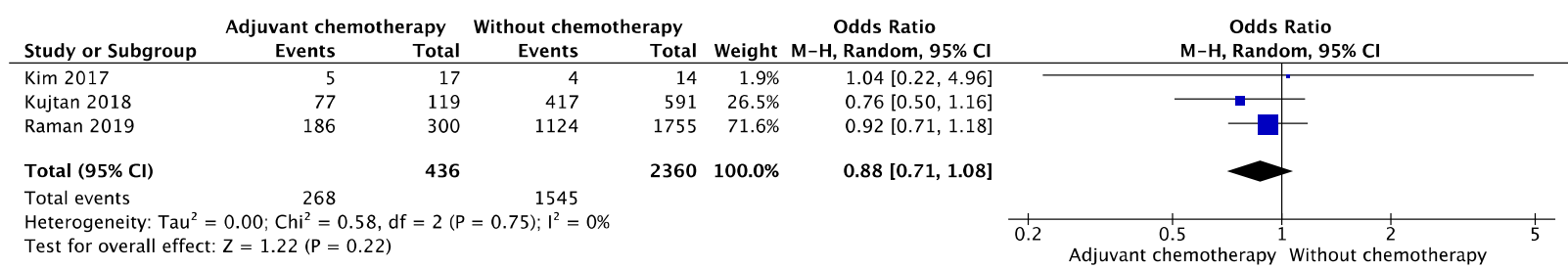

(c)

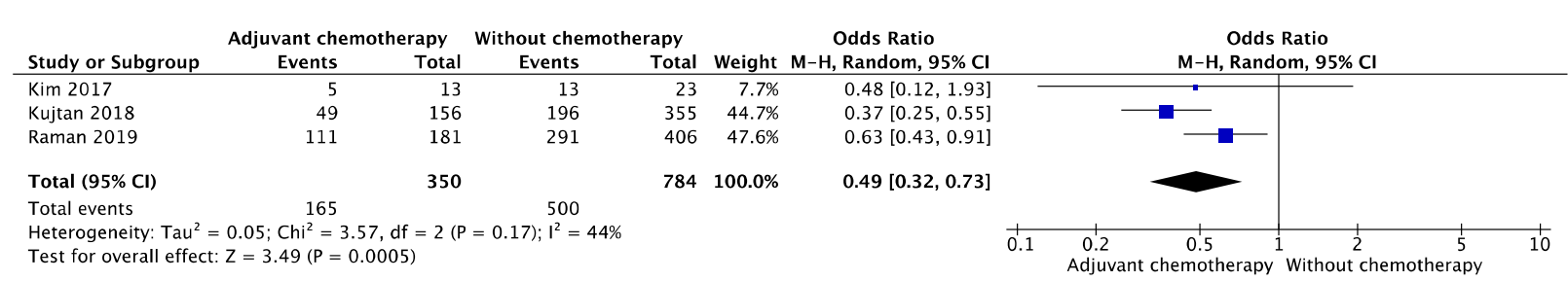

Figure 2. Subgroup analysis of adjuvant chemotherapy in early stage. (a) The odds ratio of adjuvant chemotherapy in patients with stage IA; (b) odds ratio of adjuvant chemotherapy in patients with stage IB; (c) odds ratio of adjuvant chemotherapy in patients with stage I.

(a)

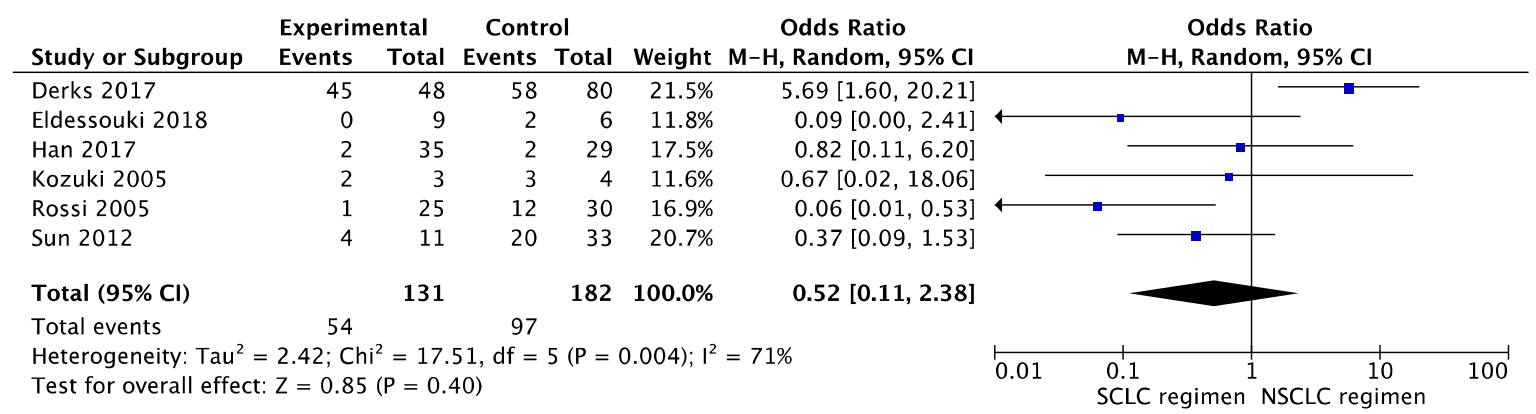

(b)

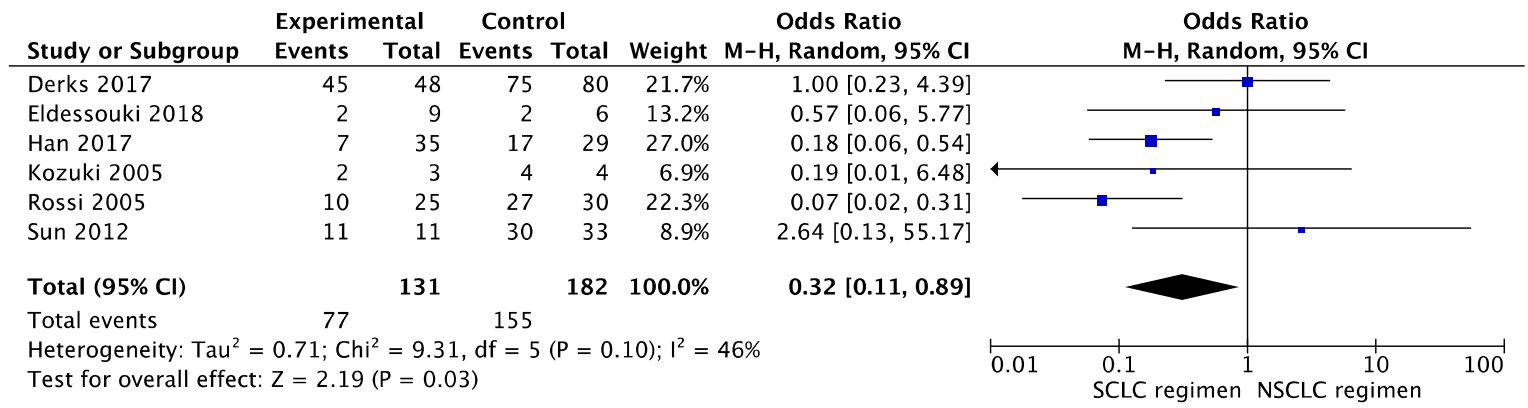

Figure 3. Different effects of chemotherapy by the SCLC or the NSCLC regimen. (a) The odds ratio of the small cell regimen versus the non-small cell regimen after one year; (b) odds ratio of the small cell regimen versus the non-small cell regimen after two years. 
There was no obvious publication bias in the meta-analysis of adjuvant chemotherapy and palliative chemotherapy because no obvious funnel plot asymmetry was observed (Figures S2-S4).

\section{Discussion}

This study evaluated the effect of adjuvant chemotherapy in 6114 cases of LCNEC that underwent resection and revealed that chemotherapy improved survival five years after chemotherapy. There was no standard regimen for adjuvant chemotherapy; the SCLC regimen was selected more frequently than the NSCLC regimen. Adjuvant chemotherapy was proved to be effective at all stages of analysis, but there was no statistical difference in patients with stage IA in the subgroup analysis. In palliative chemotherapy, the SCLC regimen showed a tendency for better survival than the NSCLC regimen after one year and was proven to have a better outcome than the NSCLC regimen after two years by comparing 301 chemotherapy patients. Generally, the SCLC regimen seemed to be a better choice than the NSCLC regimen in palliative chemotherapy of LCNEC.

The selection of the regimen for LCNEC was difficult. Moderate heterogeneity $\left(\mathrm{I}^{2}=71 \%\right)$ was observed in the OR one year after palliative chemotherapy. Chemotherapy in stage IV LCNEC reported by Derks et al. played an important role in heterogeneity. However, the trend did not seem to be the same as in other papers limited to stage III-IV patients. The mean age of patients in Derks's study seemed older than other studies. The SCLC regimen might be less effective than the NSCLC regimen in older patients with stage IV LCNEC because of its adverse effects. Some of the cases had been treated with chemoradiation therapy. Chemotherapy showed a limited effect in the treatment of LCNEC, and a combination of radiotherapy might be a potential selection for the treatment of LCNEC.

Molecular subtype-based evidence for the selection of the regimen was reported recently. Patients with LCNEC tumors that carry a wild-type RB1 gene or express the RB1 protein fare better with NSCLC-GEM/TAX treatment than with SCLC-PE chemotherapy [27]. Moreover, there was no consensus in the selection of chemotherapy for LCNEC. LCNEC is one of the rare cancers, and large-scale prospective clinical research is difficult. Unlike other pathological types of lung cancer, limited achievement has been obtained in the treatment of LCNEC. The expression and prognostic impact of programmed cell death ligand 1 (PD-L1) in LCNEC were assessed in several studies, and the high frequency of PDL1 expression could support the use of PD-L1 antibody in the treatment of LCNEC. [28,29] Evidence of the efficiency of immune checkpoint inhibitors was only observed in case reports [30-32]. There were also several case reports on the efficiency of chemotherapy by epidermal growth factor receptor tyrosine kinase inhibitors (EGFR-TKI) [33,34].

Several limitations of this study must be considered when interpreting the results. Given the nature of the rare disease of LCNEC, there were no prospective studies enrolled. Second, the effects of chemotherapy were evaluated by the OR of mortality one, two, or five years after the treatment. Hazard ratios of PFS and OS were more useful in appraising the effect of chemotherapy. Third, there was only one study that adjusted the backgrounds of patients enrolled in this study; there was a substantial risk of selection bias due to the nature of the observational study.

\section{Conclusions}

Adjuvant chemotherapy revealed a better outcome than surgery only, and the SCLC regimen was frequently selected. In palliative chemotherapy, the SCLC regimen showed a better effect than the NSCLC regimen.

Supplementary Materials: The following are available online at https:/ / www.mdpi.com/article / 10.3390/cancers13235948/s1, Table S1: PRISMA checklist; Figure S1: PRISMA 2009 flow diagram; Figure S2: Funnel plot of comparison of adjuvant chemotherapy; Figure S3: Funnel plot of comparison of chemotherapy by the SCLC or the NSCLC regimen at one year; Figure S4: Funnel plot of comparison of chemotherapy by the SCLC or the NSCLC regimen at two years. 
Author Contributions: H.C. and M.I. worked on data acquisition and drafting the manuscript. H.C. contributed to the study conception, data acquisition, analysis, interpretation, and drafting. H.C. and N.H. performed data acquisition, interpretation, and critical revision. H.K., R.O., S.T., T.H., Y.I., K.W. and N.S. conducted the interpretation and critical revision. All the authors provided final approval and took accountability. All authors have read and agreed to the published version of the manuscript.

Funding: This research received no external funding.

Conflicts of Interest: Nobuhiko Seki has received research grants and a speaker honorarium from Ono Pharmaceutical Company, Bristol-Myers Company, MSD, AstraZeneca, Chugai Pharmaceutical, Boehringer Ingelheim, Pfizer Japan, Eli Lilly Japan, Taiho Pharmaceutical, Daiichi Sankyo Company, and Merck Biopharma Company.

\section{References}

1. Travis, W.D.; Brambilla, E.; Burke, A.P.; Marx, A.; Nicholson, A.G. Introduction to The 2015 World Health Organization Classification of Tumors of the Lung, Pleura, Thymus, and Heart. J. Thorac. Oncol. 2015, 10, 1240-1242. [CrossRef] [PubMed]

2. Hiroshima, K.; Mino-Kenudson, M. Update on large cell neuroendocrine carcinoma. Transl. Lung Cancer Res. 2017, 6, 530-539. [CrossRef] [PubMed]

3. Fasano, M.; Della Corte, C.M.; Papaccio, F.; Ciardiello, F.; Morgillo, F. Pulmonary Large-Cell Neuroendocrine Carcinoma: From Epidemiology to Therapy. J. Thorac. Oncol. 2015, 10, 1133-1141. [CrossRef]

4. Hanna, N.; Johnson, D.; Temin, S.; Baker, S., Jr.; Brahmer, J.; Ellis, P.M.; Giaccone, G.; Hesketh, P.J.; Jaiyesimi, I.; Leighl, N.B.; et al. Systemic Therapy for Stage IV Non-Small-Cell Lung Cancer: American Society of Clinical Oncology Clinical Practice Guideline Update. J. Clin. Oncol. 2017, 35, 3484-3515. [CrossRef] [PubMed]

5. Shen, Y.; Hu, F.; Li, C.; Xu, J.; Zhong, R.; Zhang, X.; Chu, T.; Han, B. Clinical Features and Outcomes Analysis of Surgical Resected Pulmonary Large-Cell Neuroendocrine Carcinoma With Adjuvant Chemotherapy. Front. Oncol. 2020, 10, 556194. [CrossRef]

6. Sun, J.M.; Ahn, M.J.; Ahn, J.S.; Um, S.W.; Kim, H.; Kim, H.K.; Choi, Y.S.; Han, J.; Kim, J.; Kwon, O.J.; et al. Chemotherapy for pulmonary large cell neuroendocrine carcinoma: Similar to that for small cell lung cancer or non-small cell lung cancer? Lung Cancer 2012, 77, 365-370. [CrossRef]

7. George, J.; Lim, J.S.; Jang, S.J.; Cun, Y.; Ozretić, L.; Kong, G.; Leenders, F.; Lu, X.; Fernández-Cuesta, L.; Bosco, G.; et al. Comprehensive genomic profiles of small cell lung cancer. Nature 2015, 524, 47-53. [CrossRef]

8. Rekhtman, N.; Pietanza, M.C.; Hellmann, M.D.; Naidoo, J.; Arora, A.; Won, H.; Halpenny, D.F.; Wang, H.; Tian, S.K.; Litvak, A.M.; et al. Next-Generation Sequencing of Pulmonary Large Cell Neuroendocrine Carcinoma Reveals Small Cell Carcinoma-like and Non-Small Cell Carcinoma-like Subsets. Clin. Cancer Res. 2016, 22, 3618-3629. [CrossRef]

9. Derks, J.L.; van Suylen, R.J.; Thunnissen, E.; den Bakker, M.A.; Groen, H.J.; Smit, E.F.; Damhuis, R.A.; van den Broek, E.C.; Speel, E.J.M.; Dingemans, A.M.C.; et al. Chemotherapy for pulmonary large cell neuroendocrine carcinomas: Does the regimen matter? Eur. Respir. J. 2017, 49, 1601838. [CrossRef]

10. Leeflang, M.M.; Deeks, J.J.; Takwoingi, Y.; Macaskill, P. Cochrane diagnostic test accuracy reviews. Syst. Rev. 2013, 2, 82. [CrossRef]

11. Page, M.J.; McKenzie, J.E.; Bossuyt, P.M.; Boutron, I.; Hoffmann, T.C.; Mulrow, C.D.; Shamseer, L.; Tetzlaff, J.M.; Akl, E.A.; Brennan, S.E.; et al. The PRISMA 2020 statement: An updated guideline for reporting systematic reviews. BMJ 2021, $372, \mathrm{n} 71$. [CrossRef]

12. Travis, W.D.; Brambilla, E.; Nicholson, A.G.; Yatabe, Y.; Austin, J.H.M.; Beasley, M.B.; Chirieac, L.R.; Dacic, S.; Duhig, E.; Flieder, D.B.; et al. The 2015 World Health Organization Classification of Lung Tumors: Impact of Genetic, Clinical and Radiologic Advances Since the 2004 Classification. J. Thorac. Oncol. 2015, 10, 1243-1260. [CrossRef] [PubMed]

13. University Hospital Medical Information Network. Available online: https://upload.umin.ac.jp/cgi-bin/ctr/ctr_view_reg.cgi? recptno=R000050274 (accessed on 1 June 2021).

14. Stang, A. Critical evaluation of the Newcastle-Ottawa scale for the assessment of the quality of nonrandomized studies in meta-analyses. Eur. J. Epidemiol. 2010, 25, 603-605. [CrossRef]

15. Higgins, J.P.; Thompson, S.G.; Deeks, J.J.; Altman, D.G. Measuring inconsistency in meta-analyses. BMJ 2003, 327, 557-560. [CrossRef]

16. Han, K.; Yang, H.T.; Fan, L.W.; Zhao, H. Outcomes of patients with large cell neuroendocrine carcinoma of the lung after complete resection. Transl. Cancer Res. 2017, 6, 483-492. [CrossRef]

17. Kim, K.W.; Kim, H.K.; Kim, J.; Shim, Y.M.; Ahn, M.J.; Choi, Y.L. Outcomes of Curative-Intent Surgery and Adjuvant Treatment for Pulmonary Large Cell Neuroendocrine Carcinoma. World J. Surg. 2017, 41, 1820-1827. [CrossRef] [PubMed]

18. Kujtan, L.; Muthukumar, V.; Kennedy, K.F.; Davis, J.R.; Masood, A.; Subramanian, J. The Role of Systemic Therapy in the Management of Stage I Large Cell Neuroendocrine Carcinoma of the Lung. J. Thorac. Oncol. 2018, 13, 707-714. [CrossRef]

19. Ogawa, H.; Tanaka, Y.; Kitamura, Y.; Shimizu, N.; Doi, T.; Hokka, D.; Tane, S.; Nishio, W.; Yoshimura, M.; Maniwa, Y. Efficacy of perioperative chemotherapy for pulmonary high-grade neuroendocrine carcinomas: A propensity score matching analysis. $J$. Thorac. Dis. 2019, 11, 1145-1154. [CrossRef] 
20. Raman, V.; Jawitz, O.K.; Yang, C.F.J.; Tong, B.C.; D'Amico, T.A.; Berry, M.F.; Harpole, D.H. Adjuvant Therapy for Patients With Early Large Cell Lung Neuroendocrine Cancer: A National Analysis. Ann. Thorac. Surg. 2019, 108, 377-383. [CrossRef] [PubMed]

21. Rieber, J.; Schmitt, J.; Warth, A.; Muley, T.; Kappes, J.; Eichhorn, F.; Hoffmann, H.; Heussel, C.P.; Welzel, T.; Debus, J.; et al. Outcome and prognostic factors of multimodal therapy for pulmonary large-cell neuroendocrine carcinomas. Eur. J. Med. Res. 2015, 20, 64. [CrossRef]

22. Roesel, C.; Terjung, S.; Weinreich, G.; Gauler, T.; Theegarten, D.; Stamatis, G.; Welter, S. A Single-Institution Analysis of the Surgical Management of Pulmonary Large Cell Neuroendocrine Carcinomas. Ann. Thorac. Surg. 2016, 101, 1909-1914. [CrossRef] [PubMed]

23. Wakeam, E.; Adibfar, A.; Stokes, S.; Leighl, N.B.; Giuliani, M.E.; Varghese, T.K.; Darling, G.E. Defining the role of adjuvant therapy for early-stage large cell neuroendocrine carcinoma. J. Thorac. Cardiovasc. Surg. 2020, 159, 2043-2054. [CrossRef] [PubMed]

24. Eldessouki, I.; Gaber, O.; Namad, T.; Wang, J.; Morris, J.C.; Abdel Karim, N. Small or Non-Small Cell Lung Cancer Based Therapy for Treatment of Large Cell Neuroendocrine Cancer of The Lung? University of Cincinnati Experience. J. Oncol. 2018, 2018, 9761826. [CrossRef]

25. Kozuki, T.; Fujimoto, N.; Ueoka, H.; Kiura, K.; Fujiwara, K.; Shiomi, K.; Mizobuchi, K.; Tabata, M.; Hamazaki, S.; Tanimoto, M. Complexity in the treatment of pulmonary large cell neuroendocrine carcinoma. J. Cancer Res. Clin. Oncol. 2005, 131, 147-151. [CrossRef] [PubMed]

26. Rossi, G.; Cavazza, A.; Marchioni, A.; Longo, L.; Migaldi, M.; Sartori, G.; Bigiani, N.; Schirosi, L.; Casali, C.; Morandi, U.; et al. Role of chemotherapy and the receptor tyrosine kinases KIT, PDGFRalpha, PDGFRbeta, and Met in large-cell neuroendocrine carcinoma of the lung. J. Clin. Oncol. 2005, 23, 8774-8785. [CrossRef] [PubMed]

27. Derks, J.L.; Leblay, N.; Thunnissen, E.; van Suylen, R.J.; den Bakker, M.; Groen, H.J.M.; Smit, E.F.; Damhuis, R.; van den Broek, E.C.; Charbrier, A.; et al. Molecular Subtypes of Pulmonary Large-cell Neuroendocrine Carcinoma Predict Chemotherapy Treatment Outcome. Clin. Cancer Res. 2018, 24, 33-42. [CrossRef] [PubMed]

28. Ohtaki, Y.; Kaira, K.; Atsumi, J.; Nagashima, T.; Kawashima, O.; Ibe, T.; Kamiyoshihara, M.; Onozato, R.; Fujita, A.; Yazawa, T.; et al. Prognostic significance of PD-L1 expression and tumor infiltrating lymphocytes in large cell neuroendocrine carcinoma of lung. Am. J. Transl. Res. 2018, 10, 3243-3253.

29. Eichhorn, F.; Harms, A.; Warth, A.; Muley, T.; Winter, H.; Eichhorn, M.E. PD-L1 expression in large cell neuroendocrine carcinoma of the lung. Lung Cancer 2018, 118, 76-82. [CrossRef] [PubMed]

30. Takimoto Sato, M.; Ikezawa, Y.; Sato, M.; Suzuki, A.; Kawai, Y. Large cell neuroendocrine carcinoma of the lung that responded to nivolumab: A case report. Mol. Clin. Oncol. 2020, 13, 43-47. [CrossRef]

31. Wang, V.E.; Urisman, A.; Albacker, L.; Ali, S.; Miller, V.; Aggarwal, R.; Jablons, D. Checkpoint inhibitor is active against large cell neuroendocrine carcinoma with high tumor mutation burden. J. Immunother Cancer 2017, 5, 75. [CrossRef]

32. Mauclet, C.; Duplaquet, F.; Pirard, L.; Rondelet, B.; Dupont, M.; Pop-Stanciu, C.; Vander Borght, T.; Remmelink, M.; D’Haene, N.; Lambin, S.; et al. Complete tumor response of a locally advanced lung large-cell neuroendocrine carcinoma after palliative thoracic radiotherapy and immunotherapy with nivolumab. Lung Cancer 2019, 128, 53-56. [CrossRef] [PubMed]

33. Muto, S.; Ozaki, Y.; Okabe, N.; Matsumura, Y.; Hasegawa, T.; Shio, Y.; Hashimoto, Y.; Suzuki, H. Successful Treatment of Combined Large Cell Neuroendocrine Carcinoma Harboring an EGFR Mutation with EGFR-TKIs plus Bevacizumab: A Case Report. Case Rep. Oncol. 2020, 13, 1387-1392. [CrossRef] [PubMed]

34. Wang, Y.; Shen, Y.H.; Ma, S.; Zhou, J. A marked response to icotinib in a patient with large cell neuroendocrine carcinoma harboring an EGFR mutation: A case report. Oncol. Lett. 2015, 10, 1575-1578. [CrossRef] [PubMed] 